\title{
Immune factors and immunoregulation in tuberculosis
}

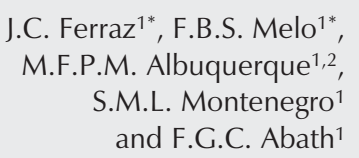

\author{
${ }^{1}$ Departamento de Imunologia, Centro de Pesquisas Aggeu Magalhães, \\ FIOCRUZ, Recife, PE, Brasil \\ ${ }^{2}$ Departamento de Medicina Tropical, Universidade Federal de Pernambuco, \\ Recife, PE, Brasil
}

\begin{abstract}
Correspondence

J.C. Ferraz

Departamento de Imunologia

Centro de Pesquisas Aggeu Magalhães FIOCRUZ

Av. Prof. Moraes Rego, s/n

50670-420 Recife, PE

Brasil

E-mail: jcferraz2002@yahoo.com

Research supported by CNPq and REDE-TB. J.C. Ferraz is the recipient of a PRODOC (Programa de Apoio a

Projetos Institucionais com a

Participação de Recém-doutores)

fellowship from CAPES.

S.M.L. Montenegro and F.G.C. Abath are recipients of $\mathrm{CNPq}$ research

scholarships.
\end{abstract}

*These authors contributed

equally to this study.

$\ldots \ldots \ldots \ldots \ldots \ldots \ldots$

Received February 6, 2006

Accepted August 21, 2006

Accepted August 21,2006

\section{Introduction}

Tuberculosis (TB) is the most frequent cause of mortality due to a single infectious disease, killing more than two million people worldwide every year (1). HIV infection increases susceptibility to TB and greatly contributes to the high number of TB patients. In 2004, nine million new cases of TB were reported. According to the World Health Organization, $80 \%$ of these new cases occurred in 22 countries in which TB is highly incident. Brazil currently ranks as the 16th most affected country (1).

The majority of human TB cases are caused by Mycobacterium tuberculosis, a slow-growing aerobic bacillus, usually intracellular and non-motile. Pathogenic mycobacteria survive in the interior of macrophages by actively inhibiting acidification of M. tuberculosis-containing phagosomes and their fusion with lysosomes. TB is a lethal disease if not treated. Therapy is lengthy and initiates with the association of four drugs (2). Low compliance with chemotherapy has been implicated in the increasing numbers of M. tuberculosis strains resistant to at least two first-line drugs (multidrug-resistant tuberculosis), an event that could effectively turn the disease uncontrollable worldwide. 
A vaccine is considered to be the best solution for controlling TB. Bacille-Calmette-Guérin (BCG), resulting from an attenuated virulent strain of $M$. bovis, is the only vaccine currently available to fight this disease and has been in use for more than 80 years. Although efficient in the prevention of serious forms of TB in infants, several clinical trials (3) have suggested that BCG does not prevent infection with the tubercle bacillus and is relatively ineffective in protecting adults against pulmonary tuberculosis. Consequently, there is an urgent need for more effective vaccines. New experimental strategies have been shown to be promising (3) but the development of efficient vaccines against TB clearly depends on a thorough understanding of the immune response displayed by the host against this pathogen.

One third of the world population is latently infected with $M$. tuberculosis and at risk of disease reactivation. After infection, a precarious balance is established between host and pathogen, and the type of immune response mounted against the bacteria will heavily influence the course of the disease. In approximately $5 \%$ of immunocompetent individuals, the infection will progress from a latent form to active disease within two years; in another 5\%, reactivation of the disease will occur later (2). The reasons for the progression to disease have not been clearly defined. On the other hand, approximately $90 \%$ of immunocompetent individuals with latent infection will most probably remain healthy and without any symptoms throughout their lifetime. These subjects mount strong immune responses, but the bacilli will most likely persist indefinitely in the host. We will review here features of the host immune response that contribute to the occurrence of the disease. In addition, the possible role of suppressive regulatory $\mathrm{T}$ lymphocytes in the failure to definitively eliminate latent $M$. tuberculosis will be discussed.

\section{Tuberculosis - clinical and pathological aspects}

TB is transmissible by infectious airborne droplets and mainly affects the lungs but it can virtually spread to any other organ or cause unchecked disseminated disease (miliary tuberculosis). It can be classified into three stages: primary, latent and secondary. Primary TB usually occurs during childhood after an initial contact with the tubercle bacillus. Frequently, it is an asymptomatic and self-limited disease. After an initial alveolitis, with infiltration of neutrophils and monocytes, a gradual arrival of Tand B-lymphocytes surrounding macrophages (some of which are infected), dendritic cells, and fibroblasts at the periphery forms the characteristic granulomatous tubercle. The tuberculous granuloma has been classically considered to be a mechanism that limits mycobacterial dissemination (4). The primary infection is often aborted at this stage, although some bacilli persist in the tissues for months or decades, without growing but still viable, a characteristic named "non-replicative persistence" (2). In cases of latent $\mathrm{TB}$, the host mounts a strong immune response, which contains but does not eliminate the infection. Failure of immune resistance mechanisms may lead to disease reactivation.

After latency, secondary tuberculosis may develop. This disease starts as an exudativeinflammatory process with pneumonic characteristics. With progression, classical symptoms such as cough, expectoration, fever, night sweats, anorexia, and loss of body weight may appear. Caseation and cavitation may be present, mainly in the upper lobes. If the infection progresses acutely, the prognosis is worse. On the other hand, if the initial infiltrate progresses to chronicity, the process may stabilize with the development of fibrosis. In this stage, the individual may survive for several years but episodic attacks of hemoptysis can be fatal (2). 


\section{Immune factors controlling tuberculosis infection}

The protective immune response against TB can be defined as Th1 since cellular immunity and production of IFN- $\gamma$ by CD4+ and CD8+ T cells are critical for disease control in animals and humans (5-7). The events related to the host innate and adaptive responses to the mycobacteria begin with the arrival of $M$. tuberculosis in the lungs. Macrophages and dendritic cells readily engulf the invading mycobacteria. In this context, the chemokine (C-C motif) receptor 2 (CCR2) plays a critical role in recruiting both cell types to the infected lungs (8). A coordinated interaction between innate and adaptive response is essential. The innate responses against the bacilli are not well understood but are clearly important since some individuals primarily exposed to $M$. tuberculosis bacilli do not get infected. Tolllike receptors (TLRs) are believed to represent key receptors recognizing mycobacterial antigens and activating macrophages and dendritic cells. TLR2 and, to a lesser extent, TLR4 are implicated in the recognition of the whole mycobacteria and purified mycobacterial lipoarabinomannans, lipomannans, phosphatidyl-myo-inositol mannoside, and the 19-kDa lipoprotein (9). In addition, most studies show a proinflammatory response resulting from this interaction (9). 1,25-D3 (the active form of vitamin D) can stimulate via TLR2/TLR1 heterodimers and vitamin D receptors the synthesis of the antimicrobial peptide LL-37 (cathelicidin), responsible for enhanced killing of $M$. tuberculosis inside the vacuoles of human activated macrophages (10). This mechanism suggests a possible explanation for the increased susceptibility to TB displayed by people with dark skin, a consequence of lower body levels of 1,25-D3 as a result of greater sunlight shielding provided by their higher melanin content (10). Interestingly, activation of TLR2 by M. tuberculosis may also induce the production of IL-10, an anti-inflammatory cytokine, and this may represent a possible mechanism of microbial evasion from adaptive responses (8). The importance of TLRs for controlling TB is also shown by mice deficient in myeloid differentiation factor 88 (an intracellular TLR-adaptor molecule), which are highly susceptible to TB infection (11). However, although these knockout mice died rapidly of infection, they were unexpectedly able to generate a specific Th1-response (11), raising questions about unknown interactions between M. tuberculosis and myeloid differentiation factor 88 .

In macrophages, $M$. tuberculosis induces an increase in mRNAs for many proinflammatory genes, particularly TNF- $\alpha$ (4). TNF$\alpha$ acts as a trigger for chemokine expression by macrophages at the site of infection, particularly CCL-2, 3, 4, 5, and CXCL9 and 10 (reviewed in Ref. 4). These chemokines bring cells to the site of infection and are important in the formation and maintenance of the granuloma. During mycobacterial infection in macrophages, apoptosis is associated with protection. Interestingly, more virulent $M$. tuberculosis strains can induce higher levels of the anti-apoptotic molecule $\mathrm{Bcl}-2$, preventing apoptosis and favoring bacterial survival (12). Deletion of the natural resistanceassociated macrophage protein gene 1 or Nrampl in murine macrophages causes susceptibility to mycobacterial infection, probably by interfering with the intracellular vesicle trafficking. The human homologue (NRAMP1, alias SLC11A1) has been associated with susceptibility to both primary and reactivational TB (13).

Transport of mycobacterial antigens from the lung to the lymph nodes is mediated by dendritic cells (but not by macrophages) and this pathway is under control of CCR5 and CCR7 (8). Interestingly, in dendritic cells, $M$. tuberculosis strongly stimulates the production of IL-12, a fact that may seem a paradox regarding intracellular bacterial sur- 
vival since IL-12 is a potent inducer of Th1 responses and is considered to be important for resistance against the disease (6).

Defects in the function of classic, mannan-binding lectin and alternative complement pathways or neutropenia have not been implicated in increased susceptibility to tuberculosis (14). In addition, although there is a strong humoral response during $\mathrm{TB}$, the role of B cells in this disease has not been well defined. However, T cell immunity is of fundamental importance in resistance against mycobacteria, as observed in patients with inherited diseases such as severe combined immunodeficiencies suffering from fatal disseminated BCG infection, and the increased risk of mycobacterial disease in patients using drugs that suppress $\mathrm{T}$ cell function (14). Because it resides in an intracytoplasmic vacuole, $M$. tuberculosis antigens are preferentially presented to $\mathrm{T}$ cells by molecules of the major histocompatibility complex (MHC) class II. Consequently, CD4+ T cells are of critical importance in the control of infection, as exhaustively demonstrated in animal models deficient in CD4+ T cells (15). In humans, the most dramatic example is represented by latently $M$. tuberculosisinfected (PPD+) HIV+ individuals, who have an 8-10\% annual risk to develop active TB, compared to a $10 \%$ lifetime risk for HIVnegative PPD+ subjects (6). Th1 cells have a primary role in the production of IFN- $\gamma$ but they may also have IFN- $\gamma$-independent functions, with TB-specific CD4+ T cells producing homotrimeric $\alpha 3$-lymphotoxin, essential for lymphocyte migration to infected sites (16).

M. tuberculosis infection results in the induction of a number of cytokines, some of them playing an essential role in resistance such as type 1 cytokines. Humans with Mendelian defects in the gene coding for the p40 subunit of IL-12 (also a subunit of IL-23) or in the $I L-12 R B 1$ gene (coding for the $B 1$ chain of the IL-12 and IL-23 receptors) are more prone to mycobacterial infection due to IL-12/IL-23 deficiency (14). IL-18 deficiency is not as critical to mycobacterial resistance as lack of IL-12, as suggested by studies in animals and humans (14). IL-12, IL-18 and IL-23 are all important inducers of IFN- $\gamma$, probably the most important cytokine regulating anti-mycobacterial defenses. Mice deficient in IFN- $\gamma$ and infected with $M$. tuberculosis rapidly die of disseminated disease, with a high bacterial load in tissues and necrotic and purulent granulomas (5). The rare individuals with mutations in the IFN-GRI or IFN-GR2 gene (coding for the IFN- $\gamma \mathrm{R} 1$ and $\mathrm{R} 2$ receptors, respectively) or IFN- $\gamma$-intracellular pathway components such as STAT1 protein, may experience fatal disseminated BCG or non-tuberculous mycobacterial infections during childhood (7). IFN- $\gamma$ is the main macrophageactivating molecule and, together with TNF$\alpha$, stimulates the production of inducible nitric oxide synthase (NOS-2), responsible for high levels of nitric oxide and other reactive nitrogen intermediates that are bactericidal to M. tuberculosis in mice (5). IFN$\gamma$ also induces expression of LRG-47, a new p47 GTPase reported to induce macrophage killing of M. tuberculosis, independently of NOS-2 (17). Together with IFN- $\gamma$, LRG-47 induces autophagy processes in macrophages, allowing these cells to overcome mycobacterial phagosome maturation block and inhibiting $M$. tuberculosis intracellular survival (18). Thus, although IFN- $\gamma$ alone cannot control $M$. tuberculosis infection, it is undoubtedly necessary for the protective responses generated against this pathogen. IFN- $\gamma$ may also induce immunopathology; a regulatory mechanism appears to be operated by IFN- $\gamma$ through nitric oxide, and controls its own actions, influencing granuloma organization and limiting excessive inflammatory responses (5).

TNF- $\alpha$ is a pleiotropic cytokine and, like IFN- $\gamma$, may play both protective and immunopathological roles during TB. Mice deficient in TNF- $\alpha$ or its receptor die of dissemi- 
nated tuberculosis with disorganized granulomas (6). Humans under therapy with TNF$\alpha$ antagonists $\left(\right.$ Infliximab $^{\circledR}$, Etanercept $^{\circledR}$ ) demonstrated increased reactivation of tuberculosis in the extrapulmonary and disseminated forms (19). TNF- $\alpha$ may also play a role in immunopathology as its augmented expression in the lungs correlates with tissue destruction (20). The effects of this cytokine suggest that its function may be dose-dependent.

CD8+ T cells are thought to be less important than $\mathrm{CD} 4+\mathrm{T}$ lymphocytes for the control of mycobacterial infection. However, mice deficient in $\beta_{2}$-microglobulin rapidly succumb to $M$. tuberculosis challenge (21), demonstrating the involvement of MHC class I-restricted $\mathrm{T}$ cells. The recently described crosspriming mechanism of CD8+ T cells in human and murine TB by mycobacterium-induced apoptotic vesicles ("detour pathway") represents a specific host activation alternative for controlling a pathogen that does not readily access the MHC-Iprocessing pathway (22). CD8+ T cells may contribute to the immune response against the tubercle bacilli by at least three mechanisms: IFN- $\gamma$ secretion (15), lysis of infected cells by Fas/Fas-ligand interaction or mediated by perforin and granzymes (23), and direct mycobactericidal activity. The latter mechanism is mediated by granulysin, an anti-mycobacterial molecule secreted by human CD8+ T cells (23). Granulysin is also found in $\mathrm{T}$ cell populations that specifically recognize the lipids and glycolipids of $M$. tuberculosis. These molecules are presented to $\mathrm{T}$ cells by $\mathrm{CD} 1$ receptors (not associated with the MHC locus) that play an important role in the immune response against human TB (22). Regarding the role of $\gamma \delta$ T cells in $\mathrm{TB}$, a major primate subset that expresses $\mathrm{V} \gamma 2$ and $\mathrm{V} \delta 2 \mathrm{~T}$-cell receptor recognizes mycobacterial phosphoantigen as part of the adaptive immune response against pathogenic mycobacteria (24). $\mathrm{V} \gamma 2 \mathrm{~V} \delta 2 \mathrm{~T}$ cells expand early during mycobacterial infection and are associated with low bacterial burdens and immunity against a fatal M. tuberculosis challenge in BCG-vaccinated monkeys. Interestingly, during chronic tuberculosis in humans, the number of $\mathrm{V} \gamma 2 \mathrm{~V} \delta 2 \mathrm{~T}$ cells is decreased (24).

If the Th1 response represents the protective pattern necessary to control TB infection, then would IL-4 and other Th1-suppressive cytokines be involved in the progression to disease? IL-4 and other markers of Th2 activity such as IgE and IgG4 are frequently found in patients with advanced tuberculosis (25). However, some animal studies do not demonstrate a clear dichotomy of the Th1-Th2 pattern in the immune response against TB (26). For instance, mice genetically deficient in IL-4 and infected with TB show bacterial loads comparable to the wild type (27). A synergistic association between IL-4 and TNF- $\alpha$ increasing disease pathology and fibrosis seems to be more important than IL-4-mediated detrimental effects on the efficacy of Th1 responses against mycobacteria (28). It still remains unclear whether IL-4 causes or simply reflects disease activity in human TB. A suppressed or poorly expressed Th1 response rather than a strong $\mathrm{Th} 2$ response has been suggested to explain the failure of immune responses to control TB. In this context, IL27 is a cytokine that promotes early Th1 development but has also been demonstrated to prevent maximal antimycobacterial containment by limiting late Th1 responses in a murine model of tuberculosis (29). Interestingly, the authors also found that IL-27/ WSX-1 pathways might inhibit serious pathological sequelae caused by excessive Th1 responses to mycobacterial infection. Thus, cytokines with a classical "proinflammatory profile" may actually have unreported inhibitory functions in cell immunity during TB infection.

On the other hand, the importance of IL10, a classical strong suppressor of Th1 (and $\mathrm{Th} 2$ ) responses, for the regulation of $\mathrm{TB}$ 
immunity has been strengthened. IL-10 is able to induce TB reactivation in animals (30). Polymorphisms in the $I L-10$ gene at position 1082 have been associated with TB in humans, particularly pleural tuberculosis (30). In addition, some human populations show increased expression of IL-10 that has been correlated with ineffective BCG vaccination (31). Similarly to IL-10, transforming growth factor- $\beta 1$ (TGF-ß1) down-regulates IFN- $\gamma$ production and is also a macrophagedeactivating cytokine produced in significant amounts by monocytes from TB patients (32). However, no association has been found to date associations between TGF- $\beta 1$ genetic polymorphisms and susceptibility to TB (30).

Although suppression of IFN- $\gamma$ (and Th1 responses) may occur due to certain inhibitory cytokines, a strong IFN- $\gamma$ production is a common feature of most antimycobacterial responses, and yet is unable to definitely eliminate M. tuberculosis from the host. In other words, although classically defined Th1 responses may be operating even during active secondary tuberculosis, this seems insufficient to guarantee that the infected host will never progress to disease. Thus, the immune responses observed in TB cannot be interpreted solely on the basis of a Th1-Th2 counter-regulatory paradigm. There is growing evidence that regulatory $T$ cells $\left(T_{\text {reg }}\right)$ may play an important role in the regulation of host immune responses against $M$. tuberculosis, as demonstrated for other infectious diseases (33).

\section{Role of regulatory $\mathbf{T}$ cells in infectious diseases}

The existence of suppressive $\mathrm{T}$ cells has been controversial until recently. In 1995, Sakaguchi and colleagues (34) demonstrated that the adoptive transfer of murine spleen cell suspensions depleted of CD4+CD25+ T cells induced intense systemic autoimmunity in athymic mice; however, co-transfer of CD4+CD25+ with CD4+CD25-negative cells completely prevented these pathologies (34). The authors concluded that the absence of a subset of CD4+ T cells expressing the $\alpha$-chain of the IL-2 receptor (CD25) was the main cause of autoimmunity. These subpopulations of suppressive $\mathrm{T}$ cells named natural $\mathrm{T}_{\text {reg }}$ cells are crucial for the dominant control of self-tolerance and fine tuning of the immune responses.

A specific transcriptional factor, denominated forkhead box p3 (FoxP3), controls the development and suppressive phenotype of $\mathrm{CD} 4+\mathrm{CD} 25+\mathrm{T}_{\text {reg }}$ cells (35). It is currently considered to be the most specific marker available for $T_{\text {reg }}$ cells from humans and mice. Neuropilin-1, a receptor involved in axon guidance, angiogenesis and activation of $\mathrm{T}$ cells, has been recently found to correlate closely with FoxP3 expression and suppressor function of $\mathrm{CD} 4+\mathrm{CD} 25+\mathrm{T}_{\mathrm{reg}}$ cells during infectious disease in mice (36). Glucocorticoid-induced TNF receptor-related gene, CTLA- 4 and CD45RO+ are auxiliary markers found in natural $T_{\text {reg }}$ populations (37). Nonetheless, the CD25 molecule is still necessary for obtaining highly purified natural $\mathrm{T}_{\text {reg }}$ cells. When human $\mathrm{CD} 4+\mathrm{T}$ cells are divided into two subsets based on the expression levels of the CD25 marker, only the population expressing the highest levels of CD25 consistently demonstrates immunosuppressive function in vitro (37).

In addition to natural $\mathrm{T}_{\text {reg }}$ cells, several subsets of regulatory $\mathrm{T}$ cells with distinct phenotypes and mechanisms of action have been described in both mice and humans. They include cross-regulatory Th1 and Th2 cells, CD4+ T cells producing TGF- $B$ (Th3), which are able to inhibit some T-cell responses in vivo, and CD4+ T regulatory 1 (Tr1) cells producing high levels of IL-10 and also able to inhibit the outcome of some autoimmune disorders (38). Because Tr1 or Th3 cells can develop from conventional CD4+ T cells when exposed to specific stimulatory conditions, they are called "induc- 
ible" $\mathrm{T}_{\mathrm{reg}}$ cells. Nevertheless, this may be somewhat misleading since natural $\mathrm{T}_{\text {reg }}$ cells expressing CD4+CD25+ and FoxP3 can also be specifically induced by foreign antigens $(33,39)$. Natural $T_{\text {reg }}$ cells are partially produced by the thymus and comprise 5-10\% of total peripheral CD4+ T cells. They become anergic upon $\mathrm{T}$-cell receptor ligation in vitro but proliferate in the presence of IL-2 in vitro and in vivo (40). Despite their apparent in vitro anergy, $\mathrm{T}_{\text {reg }}$ cell populations are capable of robust expansion in vivo and their early description as anergic cells may be mistaken. The suppressive effects of natural $\mathrm{T}_{\text {reg }}$ cells appear to be mostly mediated by cell-to-cell contact, although that may not exclude some actions mediated by cytokines (41). Human CD4+CD25+ T cells are similar to their murine counterparts (42).

Besides their function in the control of autoimmunity, natural $T_{\text {reg }}$ cells are also involved in tumor immunity, tolerance to transplants and allergic mechanisms (42). In addition, natural $\mathrm{T}_{\text {reg }}$ cells have been reported to play a role in immune responses against invading microbes (33). It was initially observed that depletion of CD4+CD25+ T cells induced severe pneumonitis in mice infected with Pneumocystis carinii (43), suggesting an essential role for $\mathrm{T}_{\text {reg }}$ cells in controlling the immunopathology caused by this fungus. Concomitantly, Belkaid and colleagues (44) demonstrated the importance of natural $\mathrm{T}_{\text {reg }}$ cells accumulated at sites of infection in maintaining chronic disease by Leishmania major in a murine model. In fact, with the function of $\mathrm{T}_{\text {reg }}$ cells abolished, sterile immunity to L. major was reached, although these animals were more prone to reinfection (44). Very recently, it has been demonstrated that natural $\mathrm{T}_{\text {reg }}$ cells are able to respond specifically to Leishmania antigens at the infected sites and that their survival is strictly dependent on parasite persistence (39). In another example, mice depleted of $\mathrm{CD} 4+\mathrm{CD} 25+\mathrm{T}_{\text {reg }}$ cells were able to counteract immunosuppression caused by Plasmo- dium yoelii and resisted a lethal infection with virulent strains of this parasite (45). In summary, depletion of $\mathrm{T}_{\text {reg }}$ cells can lead to complete elimination of pathogens which otherwise establish chronic or latent infections in the host. However, this state may prevent long-term protection of the host due to ineffective maintenance of memory cells (33). The Th2 response is associated with protection against lethal inflammatory pathology caused by Th1 responses during the acute phase of schistosomiasis in mice. In this model, natural $\mathrm{T}_{\text {reg }}$ cells producing IL10 were implicated as major players driving a Th 2 response by inhibiting IL-12 produced by activated dendritic cells and increasing host survival (46). Thus, in this context, triggering of CD4+CD25+ $\mathrm{T}_{\text {reg }}$ cells is advantageous to protect the host against excessive Th1 immunopathology although it may not lead to total elimination of the parasite.

Studies in humans have also suggested a role for natural $\mathrm{T}_{\text {reg }}$ cells in the balance between immunopathology and the persistence of pathogens. Natural $\mathrm{T}_{\text {reg }}$ cells isolated from individuals chronically infected with Helicobacter pylori are able to suppress $H$. pylo$r i$-specific $\mathrm{T}$ cell responses but not responses to unrelated antigens such as tetanus toxoid (47). Chronic infection with HIV also induces specifically suppressive natural $T_{\text {reg }}$ cells (48). Individuals chronically infected with hepatitis $C$ virus have a higher number of circulating natural $\mathrm{T}_{\text {reg }}$ cells than uninfected subjects, and depletion of $T_{\text {reg }}$ cells was found to increase specific CD8+ T cell responses in vitro (49). These findings suggest that the activation of natural $\mathrm{T}_{\mathrm{reg}}$ cells is capable of avoiding an excessive inflammatory response to the host. However, it may also compromise the elimination of the pathogen, favoring its long-term persistence. A therapeutic intervention in this balanced system would be successful if a perfect equilibrium between effectors and suppressive $\mathrm{T}$ cell responses beneficial to the host could be achieved. 


\section{Is there a role for regulatory $\mathbf{T}$ cells in tuberculosis?}

In spite of intense research on the immune response elicited during tuberculosis, the mechanisms involved in the development of active disease remain obscure. It is becoming clear that naturally occurring $\mathrm{CD} 4+\mathrm{CD} 25+\mathrm{T}_{\text {reg }}$ cells not only influence self-antigen-specific immune responses but also inhibit foreign antigen-specific immunity in infectious diseases (39). However, direct evidence of immunoregulatory properties of $T_{\text {reg }}$ cells in human or experimental tuberculosis is scarce $(50,51)$, and most of the discussion on the participation of $\mathrm{T}_{\text {reg }}$ cells in tuberculosis is derived from indirect evidence.

The immune response in TB is sometimes characterized by active immunosuppression, particularly in severe disease, as evidenced by decreased production of IL-2 and IFN- $\gamma$ and antigen-specific anergy to preparations of PPD $(52,53)$. This has also been correlated with expansion of IL-10producing $T$ cells (52). TGF- $\beta 1$, another pleiotropic cytokine with suppressive effects against cell immunity, has been frequently detected in patients with active TB, particularly in the granulomatous lung lesions (32). On the other hand, TGF- $\beta 1$ is an important factor for the survival, retention and function of natural $\mathrm{T}_{\text {reg }}$ cells (54). In addition, high concentrations of TGF- $\beta$ have been reported to convert conventional $\mathrm{CD} 4+\mathrm{T}$ cells into FoxP3-expressing suppressive $\mathrm{T}$ cells (55). IL-4 is frequently found in advanced TB and the action of this cytokine can enhance the suppressive effects of $\mathrm{CD} 4+\mathrm{CD} 25+\mathrm{T}_{\text {reg }}$ cells on CD4+CD25-negative cells (56). Thus, inhibitory cytokines can be correlated with susceptibility to infection and disease and, at the same time, may also suggest involvement of $\mathrm{T}_{\text {reg }}$ cells in this process. The infection by $M$. tuberculosis generates a certain degree of concomitant immunity but not so potent because reinfec- tion does occur (57). Whether $\mathrm{T}_{\text {reg }}$ cells are involved in this process, as suggested for other chronic diseases (33), is still unknown.

Very recently, two papers have addressed more directly the role of $\mathrm{T}_{\text {reg }}$ cells in human TB (50,51). Ribeiro-Rodrigues and colleagues (50) reported that frequencies of both total CD4+CD25+ T cells and CD4+ $\mathrm{CD} 25^{\text {high }}$ (probably representing true regulatory T cells, because the expression of FoxP3 in $T_{\text {reg }}$ cells was not analyzed) are increased during active human TB, and that this increase is sustained even upon completion of TB treatment. Nonetheless, this study was not able to show a correlation between clinical profiles and frequencies of $\mathrm{T}_{\text {reg }}$ cells. These cells may play a role in the prolonged suppression of IFN- $\gamma$ production in response to mycobacterial antigens in human TB. Guyot-Revol and colleagues (51), using the two most accurate available markers for $T_{\text {reg }}$ cells, i.e., high levels of cell surface CD25 expression and FoxP3 mRNA expression, found a significantly higher percentage of circulating $\mathrm{CD} 4+\mathrm{CD} 25^{\text {high }} \mathrm{T}$ cells and an increased level of FoxP3 mRNA in peripheral blood mononuclear cells (PBMC) from TB patients. Moreover, there was a positive correlation between these two markers, and FoxP3 was almost exclusively expressed by $\mathrm{CD} 4+\mathrm{CD} 25^{\text {high }} \mathrm{T}$ cells. The increase in the number of IFN- $\gamma$-secreting T cells detected after specific depletion of $\mathrm{CD} 25^{\text {high }}$ cells confirmed that $\mathrm{T}_{\text {reg }}$ cells from TB patients do have regulatory activity (51). More importantly, high concentrations of $T_{\text {reg }}$ cells were detected at sites of active inflammation and tissue pathology (pleural, ascitic and pericardial fluids), suggesting that these cells may play a role in limiting immune-mediated pathology. In agreement with this, Ribeiro-Rodrigues and colleagues (50) also showed that $\mathrm{T}_{\text {reg }}$ cells were compartmentalized in the TB-involved lung in comparison to the uninvolved lung.

In addition, Guyot-Revol and colleagues (51) demonstrated that higher levels of FoxP3 
expression were observed in PBMC from patients with extrapulmonary disease compared with patients who had purely pulmonary disease. Extrapulmonary dissemination can represent a failure to maintain localized disease within the organ of primary infection, and is associated with a suppressed Th1-type immune response. PBMC from active TB patients expressed higher levels of IL-10 and TGF- 31 than PBMC from healthy controls. Nevertheless, there was no preferential expression of these cytokines in CD4+ $\mathrm{CD} 25^{\text {high }} \mathrm{T}$ cells, suggesting that these cells are not IL-10 Tr1- or TGF-ß1-producing Th3 cells (51).

The bacteriologic or sterile cure of human TB is a polemic issue. It is very likely that patients considered to be clinically cured would eventually join the enormous group of individuals carrying the bacteria in the latent stage and at risk of disease reactivation. In public health terms, this is a huge problem. Some researchers think that during latent infection dormant $M$. tuberculosis is likely to impair effector functions of infected macrophages and dendritic cells, to exhaust effector $\mathrm{T}$ cells and to stimulate regulatory $\mathrm{T}$ cells (58). The experimental depletion of $\mathrm{CD} 4+\mathrm{CD} 25+\mathrm{T}_{\text {reg }}$ cells stimulates a more effective response of CD4+ CD25-negative cells in the eradication of pathogens such as Leishmania and Plasmodium (33). Investigating the role of antigenspecific $\mathrm{T}_{\text {reg }}$ cells during human TB could be important for future studies of clinically con- trolled immunoregulation of the disease in an attempt to induce sterile cure. Clinical protocols for therapeutic intervention of $\mathrm{T}_{\text {reg }}$ cells in human diseases are being investigated (59). Additionally, the identification of antigens responsible for the mobilization of $\mathrm{T}_{\text {reg }}$ cell populations (49) could contribute to the treatment of immunoregulatory disorders and to vaccination studies. Regarding the former, M. vaccae, a saprophytic mycobacterium, significantly reduces murine allergic pulmonary inflammation by inducing CD4+CD45RB ${ }^{\text {low }}$ and pulmonary CD11c+ cells that secrete IL-10 and TGF- $\$ 1$. These cytokines play a significant role in the differentiation and effector function of $\mathrm{T}_{\text {reg }}$ cells (60). Because of its genetic similarity to $M$. tuberculosis, it is equally possible that $\mathrm{BCG}$ vaccination could induce populations of $T_{\text {reg }}$ cells. Consequently, studies on vaccines against tuberculosis would have to address the role of $\mathrm{T}_{\text {reg }}$ cells during vaccination. Finally, therapeutic manipulation of $\mathrm{T}_{\text {reg }}$ cells exhibits several ways to fight effectively against chronic infectious diseases such as malaria, AIDS and TB. However, reaching this aim still requires a deep knowledge of the specific immune response of each infectious disease.

\section{Acknowledgments}

We are thankful to the referees for their critical comments and valuable suggestions.

\section{References}

1. World Health Organization. The Stop TB Department. WHO Report 2006: Global Tuberculosis Control - surveillance, planning, financing. [http://www.who.int/tb/publications/global_report/2006/ download_centre/en/index.html]. 2005.

2. Small PM, Fujiwara PI. Management of tuberculosis in the United States. N Engl J Med 2001; 345: 189-200.

3. Ferraz JC, Stavropoulos E, Yang M, Coade S, Espitia C, Lowrie DB, et al. A heterologous DNA priming-Mycobacterium bovis BCG boosting immunization strategy using mycobacterial Hsp70, Hsp65, and Apa antigens improves protection against tuberculosis in mice. In- fect Immun 2004; 72: 6945-6950.

4. Algood HM, Chan J, Flynn JL. Chemokines and tuberculosis. Cytokine Growth Factor Rev 2003; 14: 467-477.

5. Cooper AM, Adams LB, Dalton DK, Appelberg R, Ehlers S. IFNgamma and NO in mycobacterial disease: new jobs for old hands. Trends Microbiol 2002; 10: 221-226.

6. Flynn JL. Immunology of tuberculosis and implications in vaccine development. Tuberculosis 2004; 84: 93-101.

7. Ottenhoff TH, Verreck FA, Hoeve MA, van de Vosse E. Control of human host immunity to mycobacteria. Tuberculosis 2005; 85: 53-64. 
8. Salgame P. Host innate and Th1 responses and the bacterial factors that control Mycobacterium tuberculosis infection. Curr Opin Immunol 2005; 17: 374-380.

9. Quesniaux V, Fremond C, Jacobs M, Parida S, Nicolle D, Yeremeev $\mathrm{V}$, et al. Toll-like receptor pathways in the immune responses to mycobacteria. Microbes Infect 2004; 6: 946-959.

10. Liu PT, Stenger S, Li H, Wenzel L, Tan BH, Krutzik SR, et al. Toll-like receptor triggering of a vitamin D-mediated human antimicrobial response. Science 2006; 311: 1770-1773.

11. Fremond CM, Yeremeev V, Nicolle DM, Jacobs M, Quesniaux VF, Ryffel B. Fatal Mycobacterium tuberculosis infection despite adaptive immune response in the absence of MyD88. J Clin Invest 2004; 114: 1790-1799.

12. Rios-Barrera VA, Campos-Pena V, Aguilar-Leon D, Lascurain LR, Meraz-Rios MA, Moreno J, et al. Macrophage and $\mathrm{T}$ lymphocyte apoptosis during experimental pulmonary tuberculosis: their relationship to mycobacterial virulence. Eur J Immunol 2006; 36: 345353.

13. Malik S, Abel L, Tooker H, Poon A, Simkin L, Girard M, et al. Alleles of the NRAMP1 gene are risk factors for pediatric tuberculosis disease. Proc Natl Acad Sci U S A 2005; 102: 12183-12188.

14. Doffinger R, Patel S, Kumararatne DS. Human immunodeficiencies that predispose to intracellular bacterial infections. Curr Opin Rheumatol 2005; 17: 440-446.

15. Roach DR, Briscoe H, Saunders B, France MP, Riminton S, Britton WJ. Secreted lymphotoxin-alpha is essential for the control of an intracellular bacterial infection. J Exp Med 2001; 193: 239-246.

16. Tascon RE, Stavropoulos E, Lukacs KV, Colston MJ. Protection against Mycobacterium tuberculosis infection by CD8+ T cells requires the production of gamma interferon. Infect Immun 1998; 66: 830-834.

17. MacMicking JD, Taylor GA, McKinney JD. Immune control of tuberculosis by IFN-gamma-inducible LRG-47. Science 2003; 302: 654659.

18. Gutierrez MG, Master SS, Singh SB, Taylor GA, Colombo MI, Deretic V. Autophagy is a defense mechanism inhibiting BCG and Mycobacterium tuberculosis survival in infected macrophages. Cell 2004; 119: 753-766.

19. Wallis RS, Broder MS, Wong JY, Hanson ME, Beenhouwer DO. Granulomatous infectious diseases associated with tumor necrosis factor antagonists. Clin Infect Dis 2004; 38: 1261-1265.

20. Lasco TM, Cassone L, Kamohara H, Yoshimura T, McMurray DN. Evaluating the role of tumor necrosis factor-alpha in experimental pulmonary tuberculosis in the guinea pig. Tuberculosis 2005; 85: 245-258.

21. Flynn JL, Goldstein MM, Triebold KJ, Koller B, Bloom BR. Major histocompatibility complex class I-restricted $\mathrm{T}$ cells are required for resistance to Mycobacterium tuberculosis infection. Proc Natl Acad Sci U S A 1992; 89: 12013-12017.

22. Winau F, Weber S, Sad S, de Diego J, Hoops SL, Breiden B, et al. Apoptotic vesicles crossprime CD8 $\mathrm{T}$ cells and protect against tuberculosis. Immunity 2006; 24: 105-117.

23. Grotzke JE, Lewinsohn DM. Role of CD8+ T lymphocytes in control of Mycobacterium tuberculosis infection. Microbes Infect 2005; 7: 776-788.

24. Chen ZW. Immune regulation of gammadelta $T$ cell responses in mycobacterial infections. Clin Immunol 2005; 116: 202-207.

25. Lienhardt C, Azzurri A, Amedei A, Fielding K, Sillah J, Sow OY, et al. Active tuberculosis in Africa is associated with reduced Th1 and increased Th2 activity in vivo. Eur J Immunol 2002; 32: 1605-1613.

26. Jung YJ, LaCourse R, Ryan L, North RJ. Evidence inconsistent with a negative influence of $\mathrm{T}$ helper 2 cells on protection afforded by a dominant $\mathrm{T}$ helper 1 response against Mycobacterium tuberculosis lung infection in mice. Infect Immun 2002; 70: 6436-6443.

27. North RJ. Mice incapable of making IL-4 or IL-10 display normal resistance to infection with Mycobacterium tuberculosis. Clin Exp Immunol 1998; 113: 55-58

28. Rook GA, Hernandez-Pando R, Dheda K, Teng SG. IL-4 in tuberculosis: implications for vaccine design. Trends Immunol 2004; 25 : 483-488.

29. Holscher C, Holscher A, Ruckerl D, Yoshimoto T, Yoshida H, Mak T, et al. The IL-27 receptor chain WSX-1 differentially regulates antibacterial immunity and survival during experimental tuberculosis. $J$ Immunol 2005; 174: 3534-3544.

30. Henao MI, Montes C, Paris SC, Garcia LF. Cytokine gene polymorphisms in Colombian patients with different clinical presentations of tuberculosis. Tuberculosis 2006; 86: 11-19.

31. Weir RE, Black GF, Dockrell HM, Floyd S, Fine PE, Chaguluka SD, et al. Mycobacterial purified protein derivatives stimulate innate immunity: Malawians show enhanced tumor necrosis factor alpha, interleukin-1beta (IL-1beta), and IL-10 responses compared to those of adolescents in the United Kingdom. Infect Immun 2004; 72: 18071811.

32. Toossi Z, Gogate P, Shiratsuchi H, Young T, Ellner JJ. Enhanced production of TGF-beta by blood monocytes from patients with active tuberculosis and presence of TGF-beta in tuberculous granulomatous lung lesions. J Immunol 1995; 154: 465-473.

33. Belkaid $\mathrm{Y}$, Rouse BT. Natural regulatory $\mathrm{T}$ cells in infectious disease. Nat Immunol 2005; 6: 353-360.

34. Sakaguchi S, Sakaguchi N, Asano M, Itoh M, Toda M. Immunologic self-tolerance maintained by activated $\mathrm{T}$ cells expressing IL-2 receptor alpha-chains (CD25). Breakdown of a single mechanism of self-tolerance causes various autoimmune diseases. $J$ Immunol 1995; 155: 1151-1164.

35. Hori S, Nomura T, Sakaguchi S. Control of regulatory T cell development by the transcription factor Foxp3. Science 2003; 299: 10571061.

36. Singh KP, Gerard HC, Hudson AP, Reddy TR, Boros DL. Retroviral Foxp3 gene transfer ameliorates liver granuloma pathology in Schistosoma mansoni infected mice. Immunology 2005; 114: 410-417.

37. Baecher-Allan C, Hafler DA. Suppressor T cells in human diseases. J Exp Med 2004; 200: 273-276.

38. Maggi E, Cosmi L, Liotta F, Romagnani P, Romagnani S, Annunziato F. Thymic regulatory T cells. Autoimmun Rev 2005; 4: 579-586.

39. Suffia IJ, Reckling SK, Piccirillo CA, Goldszmid RS, Belkaid Y. Infected site-restricted Foxp3+ natural regulatory $T$ cells are specific for microbial antigens. J Exp Med 2006; 203: 777-788.

40. von Boehmer H. Mechanisms of suppression by suppressor T cells. Nat Immunol 2005; 6: 338-344.

41. Maloy KJ, Salaun L, Cahill R, Dougan G, Saunders NJ, Powrie F. CD4+CD25+ T(R) cells suppress innate immune pathology through cytokine-dependent mechanisms. J Exp Med 2003; 197: 111-119.

42. Sakaguchi S. Naturally arising CD4+ regulatory T cells for immunologic self-tolerance and negative control of immune responses. Annu Rev Immunol 2004; 22: 531-562.

43. Hori S, Carvalho TL, Demengeot J. CD25+CD4+ regulatory T cells suppress CD4+ $\mathrm{T}$ cell-mediated pulmonary hyperinflammation driven by Pneumocystis carinii in immunodeficient mice. Eur $J$ Immunol 2002; 32: 1282-1291.

44. Belkaid Y, Piccirillo CA, Mendez S, Shevach EM, Sacks DL. CD4+CD25+ regulatory $\mathrm{T}$ cells control Leishmania major persistence and immunity. Nature 2002; 420: 502-507. 
45. Hisaeda H, Maekawa $\mathrm{Y}$, Iwakawa D, Okada $\mathrm{H}$, Himeno K, Kishihara $\mathrm{K}$, et al. Escape of malaria parasites from host immunity requires CD4+ CD25+ regulatory T cells. Nat Med 2004; 10: 29-30.

46. McKee AS, Pearce EJ. CD25+CD4+ cells contribute to Th2 polarization during helminth infection by suppressing Th1 response development. J Immunol 2004; 173: 1224-1231.

47. Aandahl EM, Michaelsson J, Moretto WJ, Hecht FM, Nixon DF, Lundgren A, et al. Helicobacter pylori-specific CD4+CD25 high regulatory $\mathrm{T}$ cells suppress memory $\mathrm{T}$-cell responses to $H$. pylori in infected individuals. Infect Immun 2003; 71: 1755-1762.

48. Kinter AL, Hennessey M, Bell A, Kern S, Lin Y, Daucher M, et al. CD25(+)CD4(+) regulatory $T$ cells from the peripheral blood of asymptomatic HIV-infected individuals regulate CD4(+) and CD8(+) HIV-specific $\mathrm{T}$ cell immune responses in vitro and are associated with favorable clinical markers of disease status. J Exp Med 2004; 200: 331-343.

49. Sugimoto K, Ikeda F, Stadanlick J, Nunes FA, Alter HJ, Chang KM. Suppression of HCV-specific $\mathrm{T}$ cells without differential hierarchy demonstrated ex vivo in persistent HCV infection. Hepatology 2003; 38: 1437-1448.

50. Ribeiro-Rodrigues R, Resende CT, Rojas R, Toossi Z, Dietze R, Boom $\mathrm{WH}$, et al. A role for CD4+CD25+ T cells in regulation of the immune response during human tuberculosis. Clin Exp Immunol 2006; 144: 25-34.

51. Guyot-Revol V, Innes JA, Hackforth S, Hinks T, Lalvani A. Regulatory $T$ cells are expanded in blood and disease sites in patients with tuberculosis. Am J Respir Crit Care Med 2006; 173: 803-810.

52. Goldfeld AE. Genetic susceptibility to pulmonary tuberculosis in
Cambodia. Tuberculosis 2004; 84: 76-81.

53. Delgado JC, Tsai EY, Thim S, Baena A, Boussiotis VA, Reynes JM, et al. Antigen-specific and persistent tuberculin anergy in a cohort of pulmonary tuberculosis patients from rural Cambodia. Proc Nat Acad Sci U S A 2002; 99: 7576-7581.

54. Green EA, Gorelik L, McGregor CM, Tran EH, Flavell RA. CD4+ CD25+ $T$ regulatory cells control anti-islet CD8+ $T$ cells through TGF-beta-TGF-beta receptor interactions in type 1 diabetes. Proc Natl Acad Sci U S A 2003; 100: 10878-10883.

55. Zheng SG, Wang JH, Gray JD, Soucier H, Horwitz DA. Natural and induced CD4+CD25+ cells educate CD4+. J Immunol 2004; 172 5213-5221.

56. Maerten P, Shen C, Bullens DM, Van Assche G, Van Gool S, Geboes K, et al. Effects of interleukin 4 on CD25+CD4+ regulatory $T$ cell function. J Autoimmun 2005; 25: 112-120.

57. van Rie A, Warren R, Richardson M, Victor TC, Gie RP, Enarson DA, et al. Exogenous reinfection as a cause of recurrent tuberculosis after curative treatment. N Engl J Med 1999; 341: 1174-1179.

58. Kaufmann SH. Tuberculosis: back on the immunologists' agenda. Immunity 2006; 24: 351-357.

59. Bluestone JA, Tang Q. Therapeutic vaccination using CD4+CD25+ antigen-specific regulatory T cells. Proc Natl Acad Sci U S A 2004; 101 (Suppl 2): 14622-14626.

60. Adams VC, Hunt JR, Martinelli R, Palmer R, Rook GA, Brunet LR. Mycobacterium vaccae induces a population of pulmonary CD11C+ cells with regulatory potential in allergic mice. Eur J Immunol 2004; 34: 631-638. 